\title{
Assessment of agricultural drought in Morocco based on a composite of the Vegetation Health Index (VHI) and Standardized Precipitation Evapotranspiration Index (SPEI).
}

\author{
Sara Moutia ${ }^{1,2 *}$, Mohamed Sinan ${ }^{2}$, and Brahim Lekhlif ${ }^{2}$ \\ ${ }^{1}$ DGM General Directorate of Meteorology, Morocco \\ ${ }^{2}$ EHTP Hassania School of Public Works, Morocco
}

\begin{abstract}
According to IPCC, Morocco is a highly vulnerable country to extreme climate events, especially droughts; this will affect different socioeconomic sectors, mainly the agriculture sector. Droughts are controlled by the variability of precipitation and evapotranspiration but also not neglecting the effect of land surface conditions such as land surface temperature. In this present study, the remote sense observations MODIS Normalized Difference Vegetation Index (NDVI) and CMSAF Land Surface Temperature (LST) were used for calculating the Vegetation Health Index (VHI). The main advantage of remote sensing products is that they are reasonably efficient in terms of temporal and spatial coverage, and they are useful for the monitoring and assessment of drought in the near real-time. Furthermore, ERA5 Reanalysis-based SPEI is calculated. The goal of this study is to assess the spatial and temporal patterns of drought, this study offers the composite of SPEI and VHI drought monitoring obtained by plotting maps and graphs to show the monthly and annual variability of drought for the period 2000-2015 over the whole of Morocco. This monitoring can be used as a near real-time warning system in a changing climate.
\end{abstract}

\section{Introduction}

A universal definition of drought is still missing, this makes the drought monitoring and the assessment of their severity more difficult $[1,2]$. On the other hand, drought is a central natural phenomenon causing an important loss to grain production and water supply and affecting different socio-economic sectors [3].

Morocco has been experiencing frequent droughts over the past two decades. Moreover, it is a vulnerable region to climate change, it will experience droughts rising drought frequency and intensity, and greater impacts in the future., which will mainly affect agriculture and food security [4,5]. Therefore, performant drought assessment is needed to supply efficient measures to mitigate the negative impacts.

Drought indices based on climatic parameters provide a quantitative and qualitative assessment of drought and they monitor its characteristics such as duration, amplitude, and spatial extent [6]. The Palmer Drought Severity Index (PDSI) was a crucial first step to develop drought indices, it catches the precipitation and evapotranspiration into account.[7] It has been often used to quantify dryness and wetness conditions without regard to temporal scales [8]. The Standardized Precipitation Index (SPI) comes to resolve temporal scale problems present in the PDSI, using a precipitation probabilistic approach [9]. Furthermore, the Standardized Precipitation Evapotranspiration Index considers the effect of evapotranspiration by incorporating the air temperature data, which makes it a better alternative to the PDSI and SPI.[10,11].

Drought can be also monitored effectively by satellite-based indices, they provide a synoptic area of drought occurrence including duration, intensity, and severity $[12,13]$. The Normalized Difference Vegetation Health Index (NDVI) has been the most frequently used as a representative of healthy vegetation [14]. However, it is advisable by different studies to combine this vegetation index with Land Surface Temperature (LST) to gives advantageous information as a Vegetation Health Index (VHI) [15].

The main objective of this paper is to obtain an optimal index by combining the Standardized Precipitation Evapotranspiration Index (SPEI) and Vegetation Health Index (VHI) for the period 20002015 to assess the drought events. In addition, an intercomparison of wet and dry agricultural years is presented.

\section{Study area}

Morocco is located on the northwest of the African continent, along the Atlantic Ocean and the Mediterranean Sea. It knowns a wide variety of landforms, The desert covers half of the country, mainly in the south and southeast. At the same time, agricultural land covers almost $13 \%$, it's concentrate in the north of the country. Agriculture is a very important socioeconomic sector in Morocco. It offers a significant number of jobs.

\footnotetext{
* Corresponding author: moutia.sara@gmail.com
} 


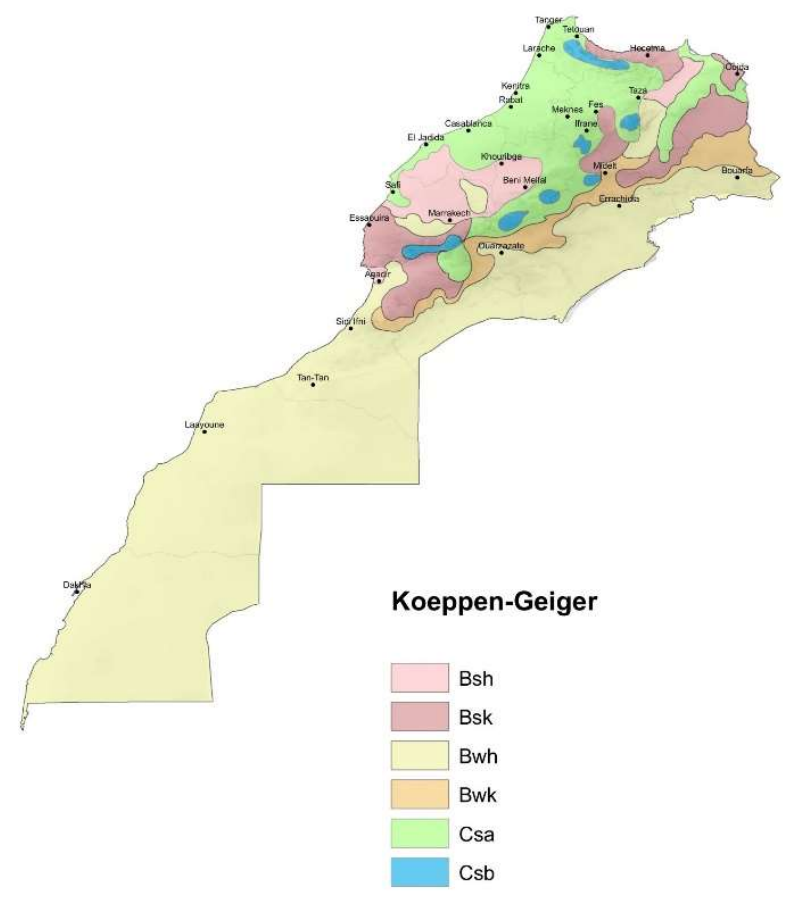

Fig. 1. Koeppen-Geiger climate classification map based on interpolated DGM ground observations data for the period 1981-2010.

Fig. 1. Represents Koeppen-Geiger Moroccan climate classification map based on interpolated data from The General Directorate of Meteorology (DGM), which serves a network of meteorological stations with high-quality measurements. As shown, the climate of Morocco varies depending on the region. The littoral north zones have a temperate (Csa) to semi-arid climate (Csb). In contrast, the climate is desertic and dry (Bwh) in the south and the south-east of the country where the rainfall is almost absent, and a relatively cold and runny climate (Csb) in the chains of mountains, Where the annual rainfall totals exceed $700 \mathrm{~mm}$ per year.

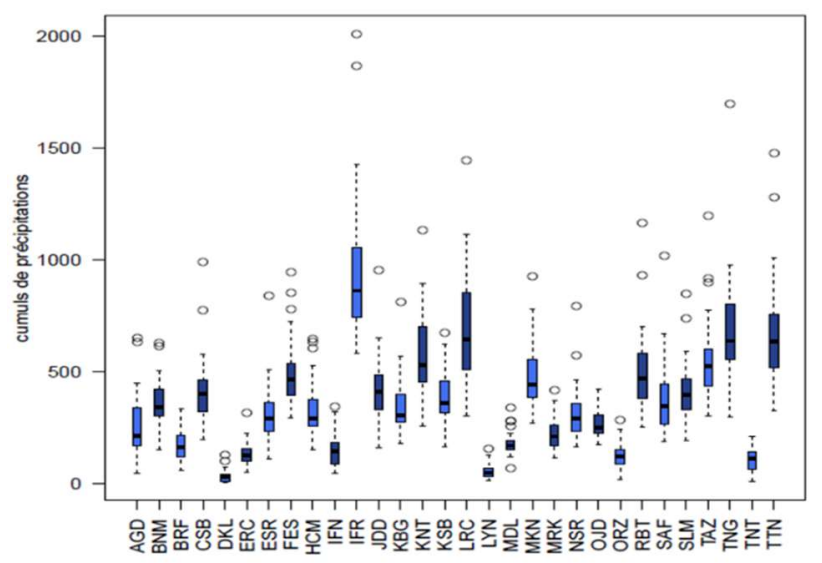

Fig. 2. Boxplots distribution of the annual rainfall at 30 DGM Meteorological Stations for the period 1981-2010.

Rainfall in Morocco illustrates a high degree of irregularity from one region to another. It's generally decreased from north to south and from west to east. In Saharian regions of the south and south-east, annual rainfall totals do not exceed $150 \mathrm{~mm}$, such as Laayoune $56.4 \mathrm{~mm}$ (LYN), and Dakhla $29.35 \mathrm{~mm}$ (DKL). In the northern half of Morocco, annual rainfalls vary between $200 \mathrm{~mm}$ and $700 \mathrm{~mm}$. The highest yearly average exceeds $700 \mathrm{~mm}$ at the mountainous station Ifrane (IFN) in the Atlas mountain range.

\section{Materials and methods}

\subsection{Methodology}

In this research, different sources of data are used, mainly the Reanalysis and satellite data. The advantage of this data is that they are good in terms of spatial and temporal coverage whereas the traditional meteorological observations are usually sparser and limited.

\subsubsection{Standardized Precipitation Evapotranspiration Index SPEI}

The SPEI characterizes drought events in the context of risen evaporative demand [10]. It is calculated as the difference between monthly precipitation based on ERA5 Reanalysis precipitation and the potential evapotranspiration using the Thornthwaite approach based on ERA5 Reanalysis $2 \mathrm{~m}$ air temperature.

The monthly SPEI data were calculated at different time scales of $1,2,3,6,9$, and 12 months, with $0.25^{\circ}$ resolution of the dataset relies on monthly air temperature and precipitation from ERA5 Reanalysis.

\subsubsection{Vegetation Health Index VHI}

Vegetation Health Index (VHI) consists to assume the vegetation and thermal conditions, it has demonstrated a vital capability to detect agricultural drought $[16,17]$. It depends on two indices, the first is the Vegetation Condition Index (VCI) based on Normalized D Vegetation Index (NDVI), which assesses the vegetation state. Secondly, the Thermal Condition Index (TCI) is based on Land Surface Temperature (LST) assessing thermal stress[18].

The LST data records used in this study are developed at CM-SAF (in a joint effort with the EUMETSAT SAF on Land Surface Analysis, LSA-SAF) from the geostationary MFG and MSG satellites using the socalled Statistical Mono-Window (SMW) algorithms, with a spatial resolution of $0.05^{\circ}[19,20]$. VHI is usually estimated by a linear combination of the two elements with equal weight. it may be written as:

$$
V H I=0.5 \times(V C I)+0.5 \times(T C I)
$$

Where VCI and TCI are defined as:

$$
\begin{gathered}
V C I=\left(N D V I-N D V I_{\min }\right) /\left(N D V I_{\max }-N D V I_{\min }\right) \\
T C I=\left(L S T-L S T_{\min }\right) /\left(L S T_{\max }-L S T_{\min }\right)
\end{gathered}
$$


For a specific month and pixel, the NDVImax and NDVImin are calculated over the climatological period of the study, respectively the same for LST.

In terms of summary, this study takes into account four monthly Climate Data Records (LST, NDVI, ERA5 Precipitation, and air temperature). Two Drought Indices SPEI and VHI were calculated and collocated over a grid of $0.25^{\circ}$ for a period of 16 years from 2000 to 2015 .

\subsubsection{Composite SPEI-VHI drought index SVI}

The drought index selected for the study is an SPEI-VHI composite index by Combining the data consisting of land variables (moisture, thermal condition) and atmospheric variables (precipitation and evapotranspiration), this may contribute to a more performant drought monitoring.

Ranking the two components into percentiles ( 0.01 to 0.99 ) allows us to consider the past events of drought. The monthly values for each element are sorted by their percentiles calculated. In this way, the SPEI and VHI are normalized by values between 0 and 1 . When the two indices are normalized we combine them by applying an equal weight.

\section{Results and discussion}

\subsection{SPEI time scale}

The NDVI is a good indicator to assess the influence of drought estimated by SPEI in the growing season of vegetation. The month of maximum NDVI is the month where the impact of thermal stress and vegetation is the strongest[2]. it is usually preferable by several studies to use VHI rather than NDVI alone, owing to $99,7 \%$ of pixels have the maximum NDVI between October and June, after masking the Desert Region for its persistent very arid character.

Then, for each SPEI time scale $(1,2,3,6,9)$ the correlation with VHI is calculated for October to June. The six months SPEI time scale that presents the maximum correlation with VHI was selected as the most appropriate for the present study, it depends on accumulated water balance for the six previous months.

\subsection{Discussion}

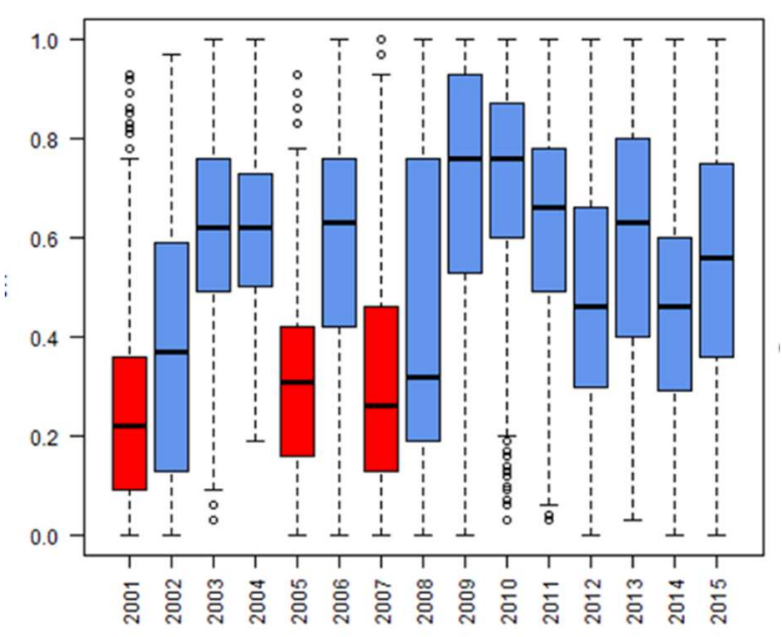

Fig. 3. Boxplot distribution of the SPEI-VHI composite drought index normalized with values between 0 and 1 for the years from 2000 to 2015 .

The amount of precipitation has an inverse impact with the agricultural drought, which influence directly the production of crops [21].

In 2000-2001 drought conditions lead the country to import around five tonnes of wheat. Again During 2005 the economic growth rate reduced from $3.5 \%$ to $1.3 \%$. One more time in 2006-2007, national cereal production was on average half of a non-drought year [4].

Results obtained in Fig. 4. show that it is possible to distinguish clearly drought years by using the composite drought index (SVI). The Fig. 4. Illustrates that the agricultural drought irregularly appears in Morocco. The drought has been visited Morocco respectively in the years with red boxes 2001, 2005, and 2007. Over this, we found that the results obtained are well confirmed. The wet Agricultural year 2008/2009 has been observed and chosen to compare it to the dry agricultural year 2006/2007, as shown in the monthly SVI maps illustration. The five classes of the composite SVI index representing the intensity of drought are shown in Table. 1:

Table 1. The five classes of the SPEI-VHI composite Index (SVI) represent an agricultural drought index.

\begin{tabular}{|c|c|}
\hline SVI values & Drought category \\
\hline $0<\mathrm{SVI}<0.2$ & Extreme drought \\
\hline $0.2<\mathrm{SVI}<0.3$ & Severe drought \\
\hline $0.3<\mathrm{SVI}<0.4$ & Moderate drought \\
\hline $0.4<\mathrm{SVI}<0.8$ & Normal \\
\hline $0.8<\mathrm{SVI}<1$ & No drought \\
\hline
\end{tabular}




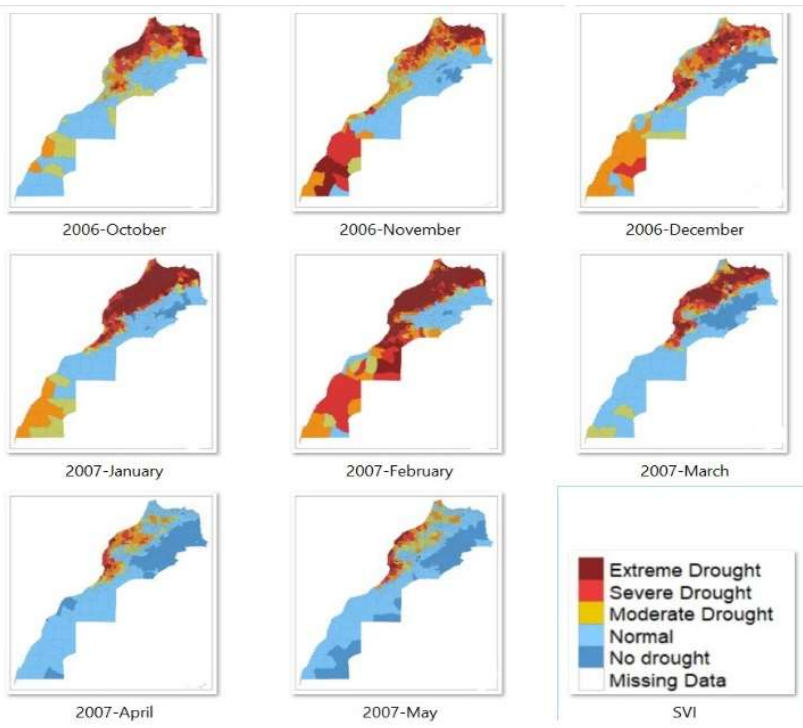

Fig. 4. Monthly SPEI-VHI composite Index(SVI) maps for the agricultural dry year 2006/2007.

Fig.4. maps of the dry year 2006/2007 show that the Regions of the north where the agriculture activities are focused were more affected by the drought. Especially for January and February, when we notice an extreme Drought, where the Saharian Region doesn't contains agricultural land.
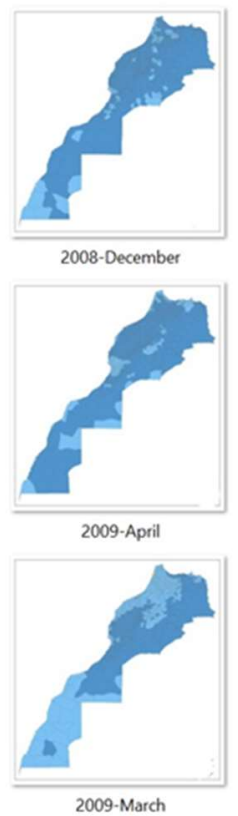
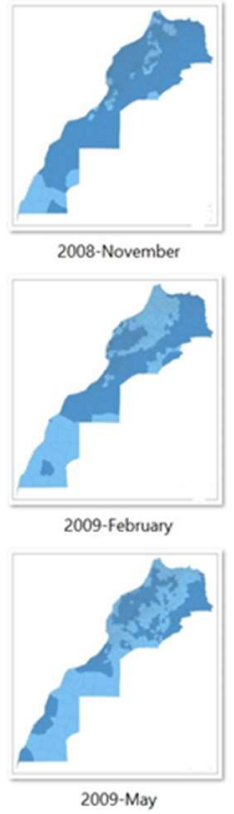
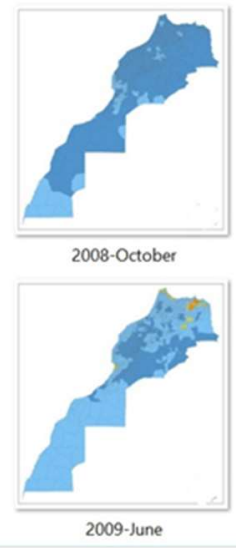

Extreme Drought Severe Drought Normal No drought Missing Data svi Moderate Drought

Fig. 5. Monthly SPEI-VHI composite Index(SVI) maps for the agricultural wet year 2008/2009.

The composite SVI drought index over Morocco for the wet year 2008/2009 is shown in Fig.5, and it observed that the no-drought category is predominant. Especially During October, November, and December. In the south and southeast of the country where the Desert and arid climate dominate. a normal drought category is observed.

The SVI maps of both wet and dry years show considerable monthly variation over the study area.

A distinct difference between the composite SVI drought index of drought year and wet year is evident from the preceding maps where the drought categories differ evidently.

\section{Conclusion}

Excellent identification of past droughts and coherent spatial distribution of drought was achieved by Combining the data of a land variable (moisture, thermal condition) measured by the VHI and atmosphere variables (precipitation and evapotranspiration) measured by SPEI.

This study can be explored as a promising first step of a near-real-time warning system for drought monitoring to bridge the gap between the climate information and the practical needs of end-users.

Further work is needed to increase the accuracy of this composite index by the quantification of its elements' weight.

\section{References}

1. A.K. Mishra, V.P. Singh, A review of drought concepts. J. Hydrol. 391, 202-216 (2010), http://dx.doi.org/10.1016/j.jhydrol.2010.07.012.

2. V.A. Bento Virgílio, C.M. Gouveia, C.C. DaCamara, I.F Trigo, Climatological assessment of drought impact on vegetation health index. Agricultural and Forest Meteorology, 259, 286295 (2018).

3. O. Rojas, A. Vrieling, F. Rembold F, Assessing drought probability for agricultural areas in Africa with coarse resolution remote sensing imagery, Remote sensing of Environment., 115, 343-52 (2011).

4. S. El Khatri, T. El Hairech.? Drought Conditions and Management Strategies in Morocco.

5. D. Verner, D. Treguer, J. Redwood, J. Christensen, R. Mcdonnell, Y.K. Elbert, S. Belghazi, Climate variability, drought, and drought management in morocco's agricultural sector, World Bank.

6. A.K. Sahoo, J. Sheffield, M.Pan, E.F Wood, Evaluation of the tropical rainfall measuring mission multi-satellite precipitation analysis (TMPA) for assessment of large-scale meteorological drought, Remote sensing of Environment., 159, 181-193 (2015).

7. Palmer, W.C. Meteorological Drought. Research Paper, 45 (1965),

https://www.ncdc.noaa.gov/temp-andprecip/drought/docs/palmer.pdf.

8. Q. Wang, P. Shi, P. T. Lei, G. Geng, J. Liu, X. Mo, X. Li, H. Zhou, J Wu, The alleviating trend of drought in the Huang-Huai-Hai plain of China based on the daily SPEI. (Int. J. Climatol), doi:10.1002/joc.4244 (2015).

9. T.B. McKee, N.J. Doesken, J. Kleist, The relationship of drought frequency and duration to time scales. In Proceedings of the 8th Conference 
on Applied Climatology, Boston, MA, USA, 1722 January (1993).

10. S.M. Vicente-Serrano, S. Beguería, J.I LópezMoreno, A multiscalar drought index sensitive to global warming: The standardized precipitation evapotranspiration index, J. Climate 23, 16961718 (2010).

11. V. Potopová, P. Štěpánek, M. Možný, L. Türkott, J. Soukup, Performance of the standardized precipitation evapotranspiration index at various lags for agricultural drought risk assessment in the Czech Republic? Agr. Forest Meteorol., 202, 2638 (2015).

12. Y. Gu, J.F. Brown, J.P Verdin, B. Wardlow, A five-year analysis of MODIS NDVI and NDWI for grassland drought assessment over the central Great Plains of the United States. Geophysical Research Letters., 34: L06407, doi:10.1029/2006GL029127 (2007).

13. A.K. Mishra, A.V.M. Ines, N.N DaS, C.P. Khedun, V.P. Singh, B. Sivakumar, J.W. Hansen JW, Anatomy of a local-scale drought: Application of assimilated remote sensing products, crop model, and statistical methods to an agricultural drought study, (Journal of Hydrology), 526:15-29 (2015).

14. J. Rhee, J. Im, G.J. Carbone? Monitoring agricultural drought for arid and humid regions using multi-sensor remote sensing data, (Remote Sensing).

15. S. Sruthi, M.A. Mohammed Aslam MAM, Agricultural drought analysis using the NDVI and land surface temperature data; a case study of Raichur District. Aquatic Procedia; 4:1258-64 (2015).

16. C. Bhuiyan, R.P. Singh, F.N. Kogan, Monitoring drought dynamics in the Aravalli region (India) using different indices based on ground and remote sensing data, (International Journal of Applied Earth Observation and Geoinformation), 289-302 (2006).

17. F.N. Kogan, Application of vegetation index and brightness temperature for drought detection, Advances in Space Research, 15(11), 91-100, (1995).

18. V.A. Bento, I.F. Trigo, C.M. Gouveia, C.C. DaCamara, Contribution of Land Surface Temperature (TCI) to Vegetation Health Index: A Comparative Study Using Clear Sky and AllWeather Climate Data Records, (remote sensing), 10, 1324 (2018).

19. A. Duguay-Tetzlaff, V. Bento, F.M. Göttsche, R. Stöckli, J. Martins, I.F. Trigo, F. Olesen, J. Bojanowski, C. da Camara, H. Kunz, Meteosat Land Surface Temperature Climate Data Record: Achievable Accuracy and Potential Uncertainties, (Remote Sensing), 7, 13139-13156 (2015).

20. K. Didan, A.B. Munoz, R. Solano, A.A. Huete, MODIS Vegetation Index User's Guide (2015).
21. D. Dutta, A. Kundu, N.R. Patel, S.K. Saha, A.R. Siddiqui, Assessment of agricultural drought in Rajasthan(India) using remote sensing derived Vegetation Condition Index (VCI) and Standardized Precipitation Index (SPI), (The Egyptian Journal of Remote Sensing and Space Sciences ), 18, 53-63 (2015). 